\section{(6) OPEN ACCESS}

\title{
Parkinson disease male-to-female ratios increase with age: French nationwide study and meta- analysis
}

\author{
Frédéric Moisan, ${ }^{1}$ Sofiane Kab, ${ }^{1,2,3}$ Fatima Mohamed, ${ }^{2,3}$ Marianne Canonico, ${ }^{2,3}$ \\ Morgane Le Guern, ${ }^{1}$ Cécile Quintin, ${ }^{4}$ Laure Carcaillon, ${ }^{4}$ Javier Nicolau, ${ }^{5}$ \\ Nicolas Duport, ${ }^{4}$ Archana Singh-Manoux, ${ }^{2,3}$ Marjorie Boussac-Zarebska, ${ }^{5}$ \\ Alexis Elbaz $1,2,3$
}

\begin{abstract}
- Additional material is published online only. To view please visit the journal online (http://dx.doi.org/10.1136/ jnnp-2015-312283).

${ }^{1}$ Département santé travail, Institut de veille sanitaire (InVS), Saint-Maurice, France ${ }^{2}$ Department of Epidemiology of ageing and age related diseases, INSERM, Centre for Research in Epidemiology and Population Health, U1018, Villejuif, France

${ }^{3}$ University Paris-Sud, UMRS 1018, Villejuif, France

${ }^{4}$ Département des maladies chroniques et des

traumatismes, Institut de veille sanitaire (InVS), Saint-Maurice, France

${ }^{5}$ Institut de veille sanitaire (InVS), Direction scientifique et de la qualité, Saint-Maurice, France
\end{abstract}

\section{Correspondence to} Dr Alexis Elbaz, INSERM U1018, Hôpital Paul Brousse, Bâtiment 15/16, 16 avenue Paul Vaillant-Couturier, Villejuif cedex 94807, France; alexis.elbaz@inserm.fr

Received 18 September 2015 Revised 12 November 2015 Accepted 15 November 2015 Published Online First 23 December 2015

\section{CrossMark}

To cite: Moisan F, Kab S, Mohamed F, et al. J Neurol Neurosurg Psychiatry 2016;87:952-957.

\section{ABSTRACT}

Background Parkinson's disease (PD) is 1.5 times more frequent in men than women. Whether age modifies this ratio is unclear. We examined whether male-to-female (M-F) ratios change with age through a French nationwide prevalence/incidence study (2010) and a meta-analysis of incidence studies.

Methods We used French national drug claims databases to identify PD cases using a validated algorithm. We computed M-F prevalence/incidence ratios overall and by age using Poisson regression. Ratios were regressed on age to estimate their annual change. We identified all PD incidence studies with age/sexspecific data, and performed a meta-analysis of $\mathrm{M}-\mathrm{F}$ ratios.

Results On the basis of 149672 prevalent (50\% women) and 25438 incident (49\% women) cases, agestandardised rates were higher in men

( prevalence $=2.865 / 1000$; incidence $=0.490 / 1000$ person-years) than women ( prevalence $=1.934 / 1000$; incidence $=0.328 / 1000$ person-years). The overall $\mathrm{M}-\mathrm{F}$ ratio was 1.48 for prevalence and 1.49 for incidence. Prevalence and incidence $\mathrm{M}-\mathrm{F}$ ratios increased by 0.05 and 0.14 , respectively, per 10 years of age. Incidence was similar in men and women under 50 years $(\mathrm{M}-\mathrm{F}$ ratio $<1.2, p>0.20)$, and over $1.6(p<0.001)$ times higher in men than women above 80 years ( $p$ trend $<0.001$ ). A meta-analysis of 22 incidence studies (14 126 cases, $46 \%$ women) confirmed that $\mathrm{M}-\mathrm{F}$ ratios increased with age $(0.26$ per 10 years, $p$ trend $=0.005)$. Conclusions Age-increasing $\mathrm{M}-\mathrm{F}$ ratios suggest that PD aetiology changes with age. Sex-related risk/ protective factors may play a different role across the continuum of age at onset. This finding may inform aetiological PD research.

\section{INTRODUCTION}

Age is the most important risk factor for neurodegenerative diseases. Increasingly, sex is recognised as having an important effect on their risk and prognosis. Over the past years, considerable attention has been paid to sex differences in the frequency, causes, symptoms, treatment response and outcomes of neurological diseases. ${ }^{1}$

After Alzheimer's disease, Parkinson's disease (PD) is the second most common neurodegenerative disease; age is its strongest risk factor. Sex also influences disease risk, PD incidence being 1.5 times higher in men than women. ${ }^{2}{ }^{3}$ There are also sex differences in disease presentation; PD may be milder in women at early stages, ${ }^{4}$ and sex-related differences in the expression of non-motor symptoms exist. ${ }^{5}$ The reasons underlying these differences are poorly understood and most likely involve a combination of genetic effects, lifestyle exposures, hormonal and reproductive factors, and differences in structure or function of the brain dopaminergic pathway. ${ }^{67}$

The role of these factors may change with age, and we therefore investigated sex differences in PD frequency by examining whether PD male-tofemale (M-F) ratios change with age, as it may provide clues to disease aetiology and guide the search for genetic and environmental risk and protective factors. Our study was made possible by the use of French National Health Insurance reimbursement databases that allowed us to identify a large number of patients with PD over the continuum of age. We also undertook a meta-analysis of incidence studies to assess whether the pattern observed in our data was consistent with findings from other studies.

\section{METHODS}

\section{Data source}

Data are drawn from the French National Health Insurance (Système National d'Information Inter-Régimes de l'Assurance Maladie, SNIIRAM) and include comprehensive anonymous information on drug reimbursements for over $97 \%$ of the French population. For each drug reimbursement, SNIIRAM provides data on the type of drug (coded using the Anatomical Therapeutic Chemical classification), date of prescription and reimbursement, total number of boxes, dosage of tablets and the medical specialisation of the prescribing physician. Demographic characteristics (age, sex, vital status) are also available. ${ }^{8}$

\section{PD cases}

Cases were identified using a prediction model that estimates the probability of being treated for PD in a given year based on drug claims. The predictors include: cumulative dose or ever use between 1 January and 31 December of antiparkinsonian 
drugs (levodopa, dopamine agonists-pramipexole, ropinirole, pergolide, apomorphine, bromocriptine, lisuride-selegiline/ rasagiline, piribedil, anticholinergics, catechol-O-methyl transferase inhibitors), proportion of the time treated, number of neurologist/general practitioner's visits and sex. This model was validated against a gold standard (clinical examination), and we have previously shown this method to identify treated cases with a sensitivity of $92.5 \%$ and specificity of $86.4 \% .{ }^{9}$

We first identified all persons with at least one antiparkinsonian drug reimbursement in 2009-2010 and excluded persons aged $<20$ years, women aged $<50$ years who were reimbursed for bromocriptine alone (lactation suppression), and persons only on anticholinergics and neuroleptics (drug-induced parkinsonism). We then applied the prediction model for the year 2010. Prevalent cases were persons predicted by the model as cases in 2010 and alive on 31 December 2010; incident cases were those persons predicted by the model as cases in 2010 who did not have antiparkinsonian drug reimbursements in 2009.

We used the sensitivity and specificity of the model to compute an overall corrected number of prevalent cases; this correction allows one to exclude false positives (eg, other causes of parkinsonism) and to correct for the imperfect sensitivity. ${ }^{10}$ The corrected number of prevalent cases by sex and 5 -year age groups was computed by assuming the same age and sex distributions for uncorrected and corrected numbers. The corrected number of incident cases was computed by assuming the same proportion of incident cases among all cases as for the uncorrected number of cases.

\section{Systematic review and meta-analysis of incidence studies}

In order to examine whether our findings were consistent with those from studies conducted in other settings using other methods, we undertook a systematic review of PD incidence studies. Two authors sought studies published before 31 January 2015, using Medline; we also searched reference lists of papers identified by this search and previous reviews for additional references. $^{2} 3$ 11-17

Studies were eligible for the meta-analysis if they included PD incidence data broken down by age and sex with at least two of three following parameters available for each age-by-sex strata in order to be able to perform calculations: number of PD cases, person-years, incidence rate. If several publications were based on the same population, we selected the most recent report.

\section{Statistical analysis}

Prevalence and incidence of PD in France

Prevalence and incidence rates (2010) were computed overall and by sex for every 5-year age group. For prevalence, we divided the corrected number of prevalent cases by the number of persons in France on 31 December 2010. ${ }^{18}$ For incidence, we divided the corrected number of incident cases by the number of person-years in France for the year 2010, which represents a valid estimate of the number of persons at risk since PD is not frequent. ${ }^{19}$

\section{$\mathrm{M}-\mathrm{F}$ prevalence and incidence ratios in France}

We computed sex-specific age-standardised PD prevalence and incidence rates using direct standardisation with the age distribution of the French population in 2010 as the reference. The overall $\mathrm{M}-\mathrm{F}$ ratio was estimated by modelling prevalence and incidence through Poisson regression adjusted for overdispersion, including sex (reference, women) and 5-year age groups as covariates and the logarithm of person-years as an offset. ${ }^{20}$ We estimated age-specific $\mathrm{M}-\mathrm{F}$ ratios by including interaction terms between sex and age groups starting at age 40 years. M-F ratios were regressed on age using weighted linear regression to estimate their annual increase.

We undertook two sets of sensitivity analyses. One, we used a PD prediction model that did not include sex as a predictor; two, we used reimbursements only for levodopa to define PD cases, as this is the main and most specific antiparkinsonian drug.

\section{Meta-analysis of PD incidence studies}

In order to compute age-specific $\mathrm{M}-\mathrm{F}$ incidence ratios for each study, we used the approach described above for each study. Since age groups were different across studies, we attributed to each age group the midpoint between its boundaries. In order to assess whether $\mathrm{M}-\mathrm{F}$ ratios progressively increased with age, we performed a pooled analysis of all studies through a multilevel Poisson regression model including a random intercept for different studies, and age, sex and their interaction as fixed effects.

We performed a random-effects meta-analysis of $\mathrm{M}-\mathrm{F}$ incidence ratios by grouping age midpoints in larger age groups (40-59, 60-79, 80+years); we tested between-study heterogeneity within age strata with the $\chi^{2}$-based $\mathrm{Q}$ statistic and quantified it using the $\mathrm{I}^{2}$ statistic. Finally, M-F incidence ratios were regressed on age midpoints using weighted linear regression to estimate their annual increase. Analyses were stratified by continent (Europe, North America, Asia) and study period (data collected before/after 2000); we tested for differences across strata by including three-way interaction terms in the Poisson multilevel model.

Analyses were performed with R3.1.0 (R Foundation for Statistical Computing, Vienna, Austria) and Stata V.13 (College Station, Texas, USA).

\section{RESULTS}

Incidence and prevalence M-F ratios (France, 2010)

Among 457027 persons with at least one reimbursement of antiparkinsonian drugs in 2010, 188562 persons were predicted as being treated for PD, of whom 10723 died in 2010 . The corrected number of prevalent cases was $149672(50 \%$ women; prevalence $=2.304 / 1000$; table 1). Among persons treated for PD in 2010, 29940 were new cases. The corrected number of incident cases was 25438 (49\% women; incidence $=0.393 / 1000$ person-years; table 2). There were no important sex differences among prevalent and incident PD cases for characteristics included in the prediction model (see online supplementary table 1 ).

Age-related changes in prevalence and incidence were similar (tables 1 and 2, see online supplementary figure 1). Estimates were consistent with results from previous prevalence and incidence studies (see online supplementary figure 1 ). PD was rare in those aged < 40 years; its frequency increased thereafter to reach a maximum between 85 and 89 years and decreased slightly after 90 years. Age-standardised rates were higher in men (prevalence $=2.865 / 1000$; incidence $=0.490 / 1000$ personyears) than women (prevalence $=1.934 / 1000$; incidence $=0.328$ / 1000 person-years). Overall, M-F ratios were 1.48 (95\% CI 1.45 to $1.51, \mathrm{p}<0.001)$ for prevalence and $1.49(95 \%$ CI 1.41 to $1.57, \mathrm{p}<0.001)$ for incidence.

M-F prevalence and incidence ratios increased markedly with age (figure 1). Prevalence ratios were below 1.3 in subjects younger than 50 years and greater than 1.5 in subjects older 
Table 1 Prevalence (per 1000) of Parkinson's disease (PD) in France in 2010

\begin{tabular}{|c|c|c|c|c|c|c|c|c|c|}
\hline \multirow[b]{2}{*}{ Age (years) } & \multicolumn{3}{|l|}{ Overall } & \multicolumn{3}{|l|}{ Men } & \multicolumn{3}{|l|}{ Women } \\
\hline & Number of PD & Population & Prevalence & Number of PD & Population & Prevalence & Number of PD & Population & Prevalence \\
\hline Unknown & 67 & - & - & 26 & - & - & 41 & - & - \\
\hline $0-4$ & 0 & 4025142 & 0.000 & 0 & 2058752 & 0.000 & 0 & 1966390 & 0.000 \\
\hline $5-9$ & 0 & 4025857 & 0.000 & 0 & 2059282 & 0.000 & 0 & 1966575 & 0.000 \\
\hline $10-14$ & 0 & 4009944 & 0.000 & 0 & 2053966 & 0.000 & 0 & 1955978 & 0.000 \\
\hline $15-19$ & 0 & 3977327 & 0.000 & 0 & 2034625 & 0.000 & 0 & 1942702 & 0.000 \\
\hline $20-24$ & 111 & 4014582 & 0.028 & 59 & 2020408 & 0.029 & 52 & 1994174 & 0.026 \\
\hline $25-29$ & 163 & 3981562 & 0.041 & 92 & 1962583 & 0.047 & 71 & 2018979 & 0.035 \\
\hline $30-34$ & 270 & 3990751 & 0.068 & 147 & 1971509 & 0.075 & 123 & 2019242 & 0.061 \\
\hline $35-39$ & 521 & 4415493 & 0.118 & 314 & 2193917 & 0.143 & 207 & 2221576 & 0.093 \\
\hline $40-44$ & 1005 & 4499436 & 0.223 & 545 & 2226922 & 0.245 & 460 & 2272514 & 0.202 \\
\hline $45-49$ & 1609 & 4527651 & 0.355 & 897 & 2226400 & 0.403 & 712 & 2301251 & 0.309 \\
\hline $50-54$ & 2942 & 4321435 & 0.861 & 1623 & 2110922 & 0.769 & 1319 & 2210513 & 0.597 \\
\hline $55-59$ & 5492 & 4169198 & 1.318 & 3141 & 2021044 & 1.554 & 2351 & 2148154 & 1.094 \\
\hline $60-64$ & 10265 & 4106061 & 2.501 & 5960 & 1987922 & 2.998 & 4305 & 2118139 & 2.032 \\
\hline $65-69$ & 12219 & 2682232 & 4.562 & 6891 & 1274392 & 5.407 & 5328 & 1407840 & 3.785 \\
\hline $70-74$ & 21129 & 2429718 & 8.696 & 11380 & 1100615 & 10.340 & 9749 & 1329103 & 7.335 \\
\hline $75-79$ & 30659 & 2267643 & 13.522 & 15967 & 952097 & 16.770 & 14692 & 1315546 & 11.168 \\
\hline $80-84$ & 32152 & 1809747 & 17.783 & 15341 & 683102 & 22.458 & 16811 & 1126645 & 14.921 \\
\hline $85-89$ & 22600 & 1170012 & 19.362 & 9602 & 377020 & 25.468 & 12998 & 792992 & 16.391 \\
\hline$\geq 90$ & 8468 & 509609 & 16.308 & 2871 & 125479 & 22.880 & 5597 & 384130 & 14.571 \\
\hline Total & 149672 & 64933400 & 2.304 & 74856 & 31440957 & 2.381 & 74816 & 33492443 & 2.234 \\
\hline
\end{tabular}

than 75 years old ( $\mathrm{p}$ linear trend $=0.006$ ), and increased by 0.05 for every 10-year age increment. Age-related changes in $\mathrm{M}-\mathrm{F}$ incidence ratios were more pronounced, and the agreement between observed and predicted values $\left(\mathrm{R}^{2}=0.972\right)$ stronger than for prevalence $\left(\mathrm{R}^{2}=0.744\right)$ (figure 1$)$. Incidence was similar in men and women younger than 50 years $(\mathrm{M}-\mathrm{F}$ ratio $<1.2, \mathrm{p}>0.20$ for all age groups), whereas it was over 1.6 $(\mathrm{p}<0.001)$ times higher in men compared to women older than 80 years ( $\mathrm{p}$ linear trend <0.001). M-F incidence ratios increased by 0.14 per 10 -year age increment. Similar results

Table 2 Incidence (per 1000 person-years) of Parkinson's disease (PD) in France in 2010

\begin{tabular}{|c|c|c|c|c|c|c|c|c|c|}
\hline \multirow[b]{2}{*}{ Age (years) } & \multicolumn{3}{|l|}{ Overall } & \multicolumn{3}{|l|}{ Men } & \multicolumn{3}{|l|}{ Women } \\
\hline & Number of PD & Person-years & Incidence & Number of PD & Person-years & Incidence & Number of PD & Person-years & Incidence \\
\hline Unknown & 43 & - & - & 19 & - & - & 24 & - & - \\
\hline $0-4$ & 0 & 3614803.5 & 0.000 & 0 & 1848187.0 & 0.000 & 0 & 1766616.5 & 0.000 \\
\hline $5-9$ & 0 & 4017184.0 & 0.000 & 0 & 2054486.5 & 0.000 & 0 & 1962697.5 & 0.000 \\
\hline 10-14 & 0 & 4004377.5 & 0.000 & 0 & 2052017.5 & 0.000 & 0 & 1952360.0 & 0.000 \\
\hline 15-19 & 0 & 3973547.0 & 0.000 & 0 & 2032155.0 & 0.000 & 0 & 1941392.0 & 0.000 \\
\hline $20-24$ & 66 & 4041247.5 & 0.016 & 36 & 2038220.5 & 0.018 & 30 & 2003027.0 & 0.015 \\
\hline $25-29$ & 73 & 3978078.5 & 0.018 & 40 & 1963707.5 & 0.020 & 33 & 2014371.0 & 0.016 \\
\hline $30-34$ & 134 & 3977767.5 & 0.034 & 70 & 1964754.5 & 0.035 & 64 & 2013013.0 & 0.032 \\
\hline $35-39$ & 224 & 4408404.5 & 0.051 & 131 & 2190139.5 & 0.060 & 93 & 2218265.0 & 0.042 \\
\hline 40-44 & 351 & 4498870.5 & 0.078 & 178 & 2226705.0 & 0.080 & 173 & 2272165.5 & 0.076 \\
\hline $45-49$ & 484 & 4532025.5 & 0.107 & 252 & 2229400.0 & 0.113 & 232 & 2302625.5 & 0.101 \\
\hline $50-54$ & 709 & 4328144.0 & 0.164 & 379 & 2114654.5 & 0.179 & 330 & 2213489.5 & 0.150 \\
\hline $55-59$ & 1103 & 4179570.0 & 0.264 & 599 & 2027808.5 & 0.295 & 504 & 2151761.5 & 0.234 \\
\hline 60-64 & 1843 & 4123817.5 & 0.447 & 1010 & 1999956.0 & 0.505 & 833 & 2123861.5 & 0.392 \\
\hline $65-69$ & 2007 & 2697942.0 & 0.744 & 1106 & 1284925.0 & 0.861 & 901 & 1413017.0 & 0.638 \\
\hline 70-74 & 3451 & 2450370.0 & 1.408 & 1907 & 1113675.0 & 1.713 & 1544 & 1336695.0 & 1.155 \\
\hline 75-79 & 4845 & 2299648.5 & 2.107 & 2525 & 970494.0 & 2.602 & 2320 & 1329154.5 & 1.745 \\
\hline $80-84$ & 5161 & 1856839.0 & 2.779 & 2568 & 706933.0 & 3.632 & 2593 & 1149906.0 & 2.255 \\
\hline $85-89$ & 3668 & 1225918.0 & 2.992 & 1658 & 400577.0 & 4.138 & 2010 & 825341.0 & 2.435 \\
\hline$\geq 90$ & 1276 & 564614.5 & 2.226 & 482 & 141448.5 & 3.406 & 794 & 423166.0 & 1.876 \\
\hline Total & 25438 & 64773169.5 & 0.393 & 12960 & 31360244.5 & 0.413 & 12478 & 33412925.0 & 0.373 \\
\hline
\end{tabular}


Figure 1 Age-specific male-to-female incidence and prevalence ratios of Parkinson's disease (France, 2010). Solid line, observed age-specific male-to-female ratios estimated by modelling prevalence and incidence through Poisson regression. Grey area, 95\% Cls of observed male-to-female ratios. Dashed line, linear regression of male-to-female ratios weighted by the inverse of their variance on age (in years, centred at 40 years).
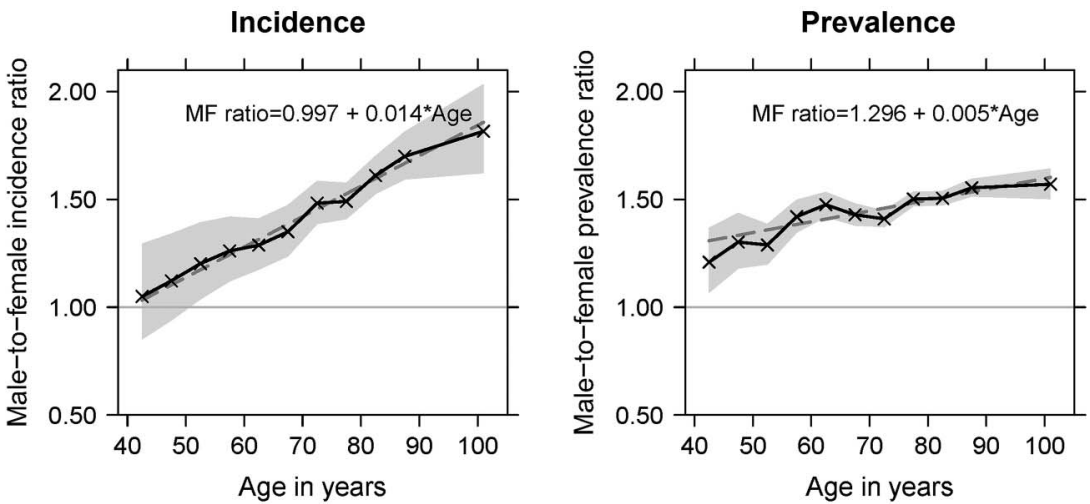

were obtained when sex was not included in the prediction model (see online supplementary figure 2) or levodopa was used as the only tracer for PD (see online supplementary figure 3).

\section{Meta-analysis of PD incidence studies}

We identified 22 eligible studies (see online supplementary table 2, supplementary figure 1; Asia, $n=4$; Europe, $n=13$; North America, $n=4$; South America, $n=1$ ) including 7616 male and 6510 female PD cases aged 40 years or older. The median (minimum/maximum) number of cases across studies was 62 (6/ 5947) for men and 58 (6/4963) for women.

The overall pooled $\mathrm{M}-\mathrm{F}$ incidence ratio was 1.57 (95\% CI 1.46 to $\left.1.68, \mathrm{p}<0.001 ; \mathrm{I}^{2}=37.1 \%, \mathrm{p}<0.001\right)$. Age-specific pooled $\mathrm{M}-\mathrm{F}$ incidence ratios increased progressively ( $\mathrm{p}$ linear trend $=0.005$ ) from 1.34 (95\% CI 1.11 to $1.61, \mathrm{p}=0.002$; $\left.\mathrm{I}^{2}=0.0 \%, \mathrm{p}=0.85\right)$ between 40 and 59 years to $1.46(95 \% \mathrm{CI}$ 1.33 to $\left.1.61, \mathrm{p}<0.001 ; \mathrm{I}^{2}=44.3 \%, \mathrm{p}=0.001\right)$ between 60 and 79 years and 1.93 (95\% CI 1.84 to $2.03, \mathrm{p}<0.001 ; \mathrm{I}^{2}=0.0 \%$, $\mathrm{p}=0.76$ ) in subjects older than 80 years (see online supplementary figure 4).

M-F incidence ratios increased by 0.26 per 10 -year age increment (figure 2). Trends in $\mathrm{M}-\mathrm{F}$ incidence ratios were similar for studies performed before and after 2000 (see online supplementary figure 5; p for interaction $=0.96$ ). In analyses stratified by continent (see online supplementary figure 6), this trend was more pronounced in Europe than North America or Asia;

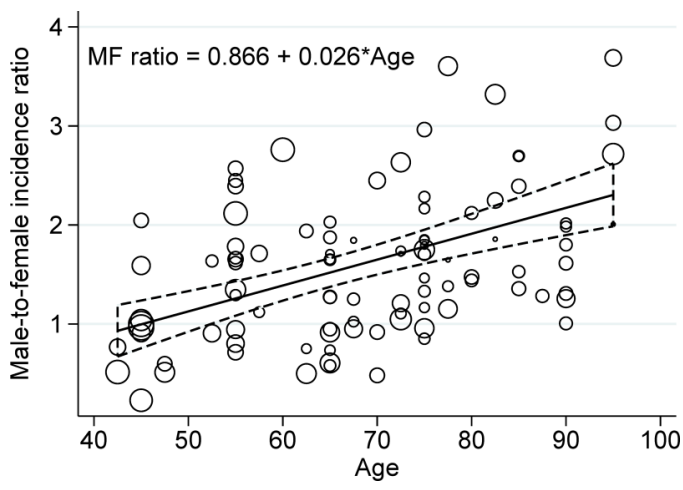

Figure 2 Systematic review of age-specific male-to-female incidence ratios of Parkinson's disease. Circles represent observed male-to-female incidence ratios for each study by age-by-sex strata, estimated by modelling incidence through Poisson regression; their size is proportional to the variance of the male-to-female incidence ratios, and more precise estimates are represented by larger circles. Solid line, linear regression of male-to-female incidence ratios weighted by the inverse of their variance on age (in years, centred at 40 years). Dashed line, $95 \% \mathrm{Cls}$ of the linear regression. however, most studies were from Europe, and the difference was not statistically significant $(p=0.87)$.

\section{DISCUSSION}

On the basis of a nationwide PD study using Health Insurance drugs reimbursement databases, we found sex differences in PD frequency to increase with age in a strikingly progressive fashion. A meta-analysis of PD incidence studies supported our findings.

Previous studies reported PD incidence to be approximately 1.5 times higher in men than women. ${ }^{2}{ }^{3}$ However, individual studies lacked the statistical power to examine age-related sex differences as the number of cases in individual studies was generally small and the age range limited (often restricted to persons 65 years and older). The median number of cases in individual incidence studies (62 for males, 58 for females) was considerably smaller than that identified in our study ( $n=25438,49 \%$ women). One previous meta-analysis of 17 incidence studies published between 1976-2006 including 2557 PD cases (median number of male and female cases combined per study $=120)$ showed that $\mathrm{M}-\mathrm{F}$ ratios were larger $(\mathrm{p}=0.018)$ in studies where mean age at onset of patients with PD was over 70 years (ratio $=1.67)$ compared to under 70 years $(\text { ratio }=1.23)^{3}$; however, this study did not examine changes in $\mathrm{M}-\mathrm{F}$ ratios within each study as only one $\mathrm{M}-\mathrm{F}$ ratio per study was available, and there was significant heterogeneity across studies within the two age groups. On the basis of a considerably larger number of patients with PD, identified using a single and validated method, we were able to model $\mathrm{M}-\mathrm{F}$ ratios as a function of 5-year age groups across the age continuum and found them to steadily increase. This pattern was more pronounced for incidence than prevalence ratios, the latter most likely being affected by sex differences in survival.

We performed a meta-analysis of studies including data broken down by sex and age groups, as well as a detailed analysis of sex and age effects which showed a similar pattern as in our study. The increase in $\mathrm{M}-\mathrm{F}$ ratios with age was more pronounced in this meta-analysis compared to our own data, but there was marked heterogeneity in estimates across studies, in particular in the 60-79 years group, which may be explained by differences across studies in age range, study design, sample sizes and populations. Similarly, M-F ratios increased with age in studies carried out before and after year 2000. This trend was more pronounced, although not statistically significantly, in Europe compared to North America and Asia; this finding needs to be examined in future studies, as the number of North American and Asian studies with age-specific and sex-specific incidence data was small.

There are several possible explanations for our findings. One, genetic contribution to $\mathrm{PD}$ is stronger at younger ages. ${ }^{21} \mathrm{PD}$ 
cases with Mendelian forms of the disease usually have a younger age of onset than non-genetic cases. Even in patients without Mendelian PD, a genetic risk score composed of multiple variants independently associated with disease risk decreases with increasing age across the continuum of age at onset, therefore showing that the accumulation of common polygenic alleles with relatively low effect sizes makes a greater contribution to early-onset than late-onset PD. ${ }^{22}$ Known PD susceptibility loci are not located on sex chromosomes, ${ }^{23}$ and there is no evidence that their effect is sex dependent; therefore, genetic susceptibility is unlikely to explain different PD rates in men and women. However, as with most multifactorial disorders, genome-wide association studies have neglected the role of $\mathrm{X}$ chromosome in PD. ${ }^{24}$ As new methods become available, it remains to be seen whether $X$ linked factors play a role in PD and whether their effect is age dependent.

Two, our findings suggest that non-genetic PD risk or protective factors are differently distributed in men and women and that their role increases with age. Which factors may account for this pattern remains unknown. Many studies have consistently shown an inverse association between smoking and PD, with a $30 \%$ risk reduction in smokers. The potential mechanisms underlying this association remain debated and it is unknown whether it is truly causal or a consequence of preclinical disease. ${ }^{25}$ Smoking is, however, unlikely to explain our findings, as smoking rates are higher in men than women. ${ }^{26}$ Men are also more often professionally exposed to chemicals (eg, pesticides, solvents), and there is some evidence that the effect of some of these may be stronger at older ages. ${ }^{27}$ Laboratory studies show that oestrogens may play a neuroprotective role, ${ }^{6}$ and, although epidemiological studies examining reproductive and hormonal factors in PD have reported somewhat inconsistent results, individual studies suggest that they may play a protective role in women. ${ }^{6} 7$ For instance, women who underwent oophorectomy are at increased risk of parkinsonism. ${ }^{28}$ The combined effect of a number of factors reflecting cumulative lifetime exposure to oestrogens shows that persistent high oestrogen levels may play a role in PD risk reduction. ${ }^{29}$ It is unknown, however, whether these factors have an agedependent effect and may explain age-dependent $\mathrm{M}-\mathrm{F}$ ratios. In fact, as endogenous oestrogen levels abruptly decrease after menopause to very low levels, a decline in $\mathrm{M}-\mathrm{F}$ ratios would be expected if they played a protective role. Amyotrophic lateral sclerosis is also more frequent in men than women, and there is some evidence that $\mathrm{M}-\mathrm{F}$ ratios decrease after menopause, which has been interpreted as loss of a protective role of endogenous oestrogens. ${ }^{30}$ The same phenomenon has been hypothesised to account, at least in part, for the observation that vascular disease rates increase in women after menopause and tend to become closer to male rates. ${ }^{31}$ There are therefore several unanswered questions and additional studies, in particular prospective cohort studies, are needed to better characterise the factors that are important, the relevant timing of exposure over the life course, and whether their role is age dependent.

Three, if sex differences in exposures associated with PD change with birth cohorts, age-dependent patterns of exposure may explain that $\mathrm{M}-\mathrm{F}$ ratios also change with age. However, this hypothesis is not supported by our meta-analysis showing that the association between $\mathrm{M}-\mathrm{F}$ incidence ratios and age does not depend on the study period. Again, smoking is unlikely to play a role, as smoking rates have increased over time in women. ${ }^{32}$ If smoking played a causal role, sex differences in PD rates would be expected to be greater at younger ages, since younger women have higher rates of smoking nowadays than their older counterparts.
Four, sexual dimorphisms in the basal ganglia that affect the number and function of dopaminergic neurons may explain the higher risk in men. ${ }^{67}$ However, it is unclear how this accounts for age-dependent $\mathrm{M}-\mathrm{F}$ ratios.

Five, selective survival can bias estimates of the association of sex with PD incidence if another unmeasured factor associated with PD interacts with sex in determining survival to old age. Therefore, selective survival may explain a widening sex difference in PD incidence over time; this is because sex and the unmeasured factor become associated as age increases, so that not taking the unmeasured factor into account will bias estimates of the association of sex with PD. ${ }^{33}{ }^{34}$ Again, smoking is unlikely to be involved, as the association between smoking and mortality is similar in men and women. ${ }^{35}$

The method used to identify PD cases is an unlikely source of bias, as prevalence and incidence rates were in agreement with published estimates. ${ }^{36}$ Sensitivity analyses yielded findings consistent with our main results, and there were no important sex differences among PD cases for characteristics included in the prediction model. We previously showed that the performances of the prediction model did not depend either on sex or age; interactions between both age and sex and other predictors included in the model building phase were not significant, therefore suggesting that PD risk associated with other predictors did not vary by age or sex and that the model performed similarly in both sexes. ${ }^{9}$ Finally, few studies have investigated whether sex influences PD diagnosis. One small pilot study in a US tertiary care centre based on patients with a relatively young PD onset showed that the duration from symptom onset to diagnosis was slightly longer in women (12.7 months) than men $(9.1$ months). ${ }^{37}$ In a population-representative UK cohort of 239 patients with incident PD, the median time from motor onset to primary care physician (PCP) presentation was longer in men (12 months) than women (8 months), but there were no sex differences in time from PCP presentation to diagnosis which was very short (1 month). ${ }^{38}$ The authors argued that the notion of men being reluctant to consult their doctor is supported by UK population surveys, showing less than half the number of PCP visits in men compared to women. To the best of our knowledge, no study has examined whether sex differences in PD diagnosis vary by age, and larger population-based studies are needed. However, given the small sex differences (a few months) observed, this is unlikely to have a significant impact on our findings as we analysed the data using 5-year age groups.

This study's main limitation is that we did not examine PD cases directly. Instead, we used a previously validated prediction model with known sensitivity and specificity that allowed us to compute corrected frequency estimates that were remarkably consistent with published ones. ${ }^{36}$ Second, our approach fails to identify patients in some institutions that have an in-house pharmacy, where medications are delivered to residents by the institution so that records are not captured by drug claims databases. However, this is an unlikely source of bias for several reasons: (1) institutions with in-house pharmacies represent about $30 \%$ of all French institutions and are not specific for patients with $\mathrm{PD}$; therefore, a small proportion of patients with PD are likely to live in institutions with in-house pharmacies; (2) our findings were stronger for incidence than prevalence, and patients with PD who are institutionalised are mainly older prevalent cases with advanced PD; (3) previous studies show that including institutionalised patients in prevalence studies does not have a major impact on frequency estimates because the majority of PD cases are not institutionalised. ${ }^{39}$ Third, our model identifies treated patients only, and does not capture 
those with untreated or undiagnosed PD. This probably contributes to the small decrease in PD frequency seen in the oldest age group ( $>85$ years) in whom PD may be more difficult to diagnose; however, age-increasing $\mathrm{M}-\mathrm{F}$ ratios were observed well before that age. Our approach may also miss patients with very early PD; however, the delay between PD onset or diagnosis and treatment is usually short: in a previous populationbased study conducted in France, the mean delay between onset and treatment was 0.80 years $(\mathrm{SD}=1.15)$ and the mean delay between diagnosis and treatment was $0.11(\mathrm{SD}=0.52) .{ }^{40}$

The main strength of this study is the ability to identify a very large number of patients from a wide age range in an exhaustive manner using a validated prediction model, and to examine the effect of age in greater detail than is possible in smaller studies.

Our findings underline the interest of administrative databases as they allow the identification of large numbers of patients and permit analyses of interactions and more complex patterns than smaller studies usually do. The age-dependent relation of PD with sex may inform the research on risk and protective factors and should encourage researchers to carefully consider the role of age and sex in PD epidemiological and genetic studies.

Contributors FrM designed the study, drafted the manuscript, and contributed to the analysis and the interpretation of the data. SK and FaM acquired the data, revised the manuscript, and contributed to the interpretation of the data. $M C, C Q$, LC, JN, ND and AS-M revised the manuscript and contributed to the interpretation of the data. MLG revised the manuscript, and contributed to the analysis and interpretation of the data. MB-Z acquired the data, revised the manuscript, and contributed to the analysis and interpretation of the data. AE designed the study, drafted the manuscript, contributed to the analysis and the interpretation of the data, obtained funding and supervised the study.

Funding SK is the recipient of a doctoral grant from the Ministry of Agriculture and sustainable development (Ministère chargé de l'agriculture et du développement durable), with financial support from the National office of water and aquatic (Office national de l'eau et des milieux aquatiques), through fees for diffuse pollution attributed to the funding of the governmental programme 'Plan Ecophyto'. FrM, CQ, $L C, J N, N D$ and $M B Z$ are InVS personnel and MC, ASM and AE are Inserm personnel.

Competing interests SK is the recipient of a doctoral grant from the Ministry of Agriculture and sustainable development (Ministère chargé de l'agriculture et du développement durable). $M C$ receives funding from the Institut de recherche en Santé Publique (IReSP) outside the submitted work. LC reports personal fees from Newron Pharmaceuticals outside the submitted work. AS-M receives research support from the NIH (NIA R01AG013196 (principal investigator), NIA R01AG034454 (principal investigator)) and the British MRC (G0902037 (coinvestigator)) outside the submitted work. AE receives funding from the French National Research Agency (ANR) and Joint Programme-Neurodegenerative Disease Research (JPND), Agence nationale de sécurité du médicament et des produits de santé (ANSM), and Institut de recherche en Santé Publique (IReSP) outside the submitted work.

Provenance and peer review Not commissioned; externally peer reviewed.

Data sharing statement All the data available are included in the paper.

Open Access This is an Open Access article distributed in accordance with the Creative Commons Attribution Non Commercial (CC BY-NC 4.0) license, which permits others to distribute, remix, adapt, build upon this work non-commercially, and license their derivative works on different terms, provided the original work is properly cited and the use is non-commercial. See: http://creativecommons.org/ licenses/by-nc/4.0/

\section{REFERENCES}

1 Rocca WA, Mielke MM, Vemuri P, et al. Sex and gender differences in the causes of dementia: a narrative review. Maturitas 2014;79:196-201.

2 Wooten GF, Currie LJ, Bovbjerg VE, et al. Are men at greater risk for Parkinson's disease than women? I Neurol Neurosurg Psychiatry 2004;75:637-9.

3 Taylor KS, Cook JA, Counsell CE. Heterogeneity in male to female risk for Parkinson's disease. J. Neurol Neurosurg Psychiatr 2007;78:905-6.

4 Haaxma CA, Bloem BR, Borm GF, et al. Gender differences in Parkinson's disease. $J$ Neurol Neurosurg Psychiatr 2007;78:819-24.

5 Liu R, Umbach DM, Peddada SD, et al. Potential sex differences in nonmotor symptoms in early drug-naive Parkinson disease. Neurology 2015;84:2107-15.

6 Gillies GE, Pienaar IS, Vohra S, et al. Sex differences in Parkinson's disease. Front Neuroendocrinol 2014;35:370-84.
7 Smith KM, Dahodwala N. Sex differences in Parkinson's disease and other movement disorders. Exp Neurol 2014:259:44-56.

8 Tuppin $\mathrm{P}$, de Roquefeuil L, WeillA, et al. French national health insurance information system and the permanent beneficiaries sample. Rev Epidemiol Sante Publique 2010;58:286-90.

9 Moisan F, Gourlet V, Mazurie JL, et al. Prediction model of Parkinson's disease based on antiparkinsonian drug claims. Am J Epidemiol 2011;174:354-63.

10 Couris CM, Colin C, Rabilloud M, et al. Method of correction to assess the number of hospitalized incident breast cancer cases based on claims databases. J Clin Epidemiol 2002:55:386-91.

11 Twelves D, Perkins KS, Counsell C. Systematic review of incidence studies of Parkinson's disease. Mov Disord 2003;18:19-31.

$12 \mathrm{Ma} \mathrm{CL}$, Su L, Xie JJ, et al. The prevalence and incidence of Parkinson's disease in China: a systematic review and meta-analysis. J Neural Transm (Vienna) 2014:121:123-34.

13 Muangpaisan W, Hori H, Brayne C. Systematic review of the prevalence and incidence of Parkinson's disease in Asia. J Epidemiol 2009;19:281-93.

14 Muangpaisan W, Mathews A, Hori $\mathrm{H}$, et al. A systematic review of the worldwide prevalence and incidence of Parkinson's disease. J Med Assoc Thai 2011:94:749-55

15 Benamer HT, de Silva R, Siddiqui KA, et al. Parkinson's disease in Arabs: a systematic review. Mov Disord 2008;23:1205-10.

16 Okubadejo NU, Bower JH, Rocca WA, et al. Parkinson's disease in Africa: a systematic review of epidemiologic and genetic studies. Mov Disord 2006;21:2150-6.

17 Wirdefeldt K, Adami HO, Cole P, et al. Epidemiology and etiology of Parkinson's disease: a review of the evidence. Eur J Epidemiol 2011;26(Suppl 1):S1-58.

18 Institut national de la statistique et des études économiques. Estimation de population. http://www.insee.fr.

19 Hill C, Doyon F. [Age in completed years versus age reached during the year]. Rev Epidemiol Sante Publique 2005;53:205-8.

20 Rothman KJ, Greenland S, Lash TL. Introduction to regression modeling. In: Wilkons LW, ed. Modern epidemiology. 3rd edn, 2008:418-55.

21 Thacker EL, Ascherio A. Familial aggregation of Parkinson's disease: a meta-analysis. Mov Disord 2008;23:1174-83.

22 Nalls MA, Escott-Price V, Williams NM, et al. Genetic risk and age in Parkinson's disease: continuum not stratum. Mov Disord 2015;30:850-4.

23 Lill CM, Roehr JT, McQueen MB, et al. Comprehensive research synopsis and systematic meta-analyses in Parkinson's Disease Genetics: the PDGene Database. PLoS Genet 2012:8:e1002548.

24 Nalls MA, Pankratz N, Lill CM, et al. Large-scale meta-analysis of genome-wide association data identifies six new risk loci for Parkinson's disease. Nat Genet 2014:46:989-93.

25 Ritz B, Rhodes SL. After half a century of research on smoking and PD, where do we go now? Neurology 2010;74:870-1.

26 Allam MF, Del Castillo AS, Navajas RF. Parkinson's disease, smoking, and gender Mov Disord 2007:22:1829-30.

27 Elbaz A, Clavel J, Rathouz PJ, et al. Professional exposure to pesticides and Parkinson's disease. Ann Neurol 2009:66:494-504.

28 Rocca WA, Bower JH, Maraganore DM, et al. Increased risk of parkinsonism in women who underwent oophorectomy before menopause. Neurology 2008;70:200-9.

29 Gatto NM, Deapen D, Stoyanoff S, et al. Lifetime exposure to estrogens and Parkinson's disease in California teachers. Parkinsonism Relat Disord 2014;20:1149-56

30 Manjaly ZR, Scott KM, Abhinav K, et al. The sex ratio in amyotrophic lateral sclerosis: a population based study. Amyotroph Lateral Scler 2010;11:439-42.

31 Barrett-Connor E. Sex differences in coronary heart disease. Why are women so superior? The 1995 Ancel Keys Lecture. Circulation 1997;95:252-64.

32 Beck F, Guignard R, Richard JB, et al. Une augmentation du tabagisme confirmée en France. La santé de l'homme 2011;411:9-10.

33 Elbaz A, Alperovitch A. Bias in association studies resulting from gene-environment interactions and competing risks. Am J Epidemiol 2002;155:265-73.

34 Glymour MM, Weuve J, Chen JT. Methodological challenges in causal research on racial and ethnic patterns of cognitive trajectories: measurement, selection, and bias. Neuropsychol Rev 2008;18:194-213.

35 Thun MJ, Carter BD, Feskanich $\mathrm{D}$, et al. 50-year trends in smoking-related mortality in the United States. N Engl J Med 2013;368:351-64.

36 Pringsheim $T$, Jette $N$, Frolkis $A$, et al. The prevalence of Parkinson's disease: a systematic review and meta-analysis. Mov Disord 2014;29:1583-90.

37 Saunders-Pullman R, Wang C, Stanley K, et al. Diagnosis and referral delay in women with Parkinson's disease. Gend Med 2011;8:209-17.

38 Breen DP, Evans JR, Farrell K, et al. Determinants of delayed diagnosis in Parkinson's disease. J Neurol 2013;260:1978-81.

39 Kowal SL, Dall TM, Chakrabarti R, et al. The current and projected economic burden of Parkinson's disease in the United States. Mov Disord 2013;28:311-8.

40 Fayard C, Bonaventure A, Benatru I, et al. Impact of recommendations on the initial therapy of Parkinson's disease: a population-based study in France. Parkinsonism Relat Disord 2011;17:543-6. 